\title{
Possibilidades da Educação Estatística como forma de análise crítica da realidade na escola indígena ${ }^{1}$
}

\author{
Possibilities of Statistical Education as a form of critical analysis of \\ reality in the indigenous school
}

\section{Posibilidades de la Educación Estadística como forma de análisis crítico de la realidad en la escuela indígena}

\section{Liliane Maria Teixeira Lima de Carualho²}

Universidade Federal de Pernambuco, Departamento de Administração Escolar e Planejamento Educacional do Centro de Educação, Professora Associada II; Docente do Curso de Graduação em Pedagogia; Professora do Programa de Pós-Graduação em Educação Matemática e Tecnológica (Edumatec)

https://orcid.org/0000-0002-7463-9662

\section{Sérgia Andréa Pereira de Oliveira ${ }^{3}$}

Universidade Federal de Pernambuco, Doutoranda em Educação Matemática e Tecnológica no Programa de Pós-Graduação em Educação Matemática e Tecnológica (Edumatec)

https://orcid.org/0000-0002-1886-8970

\section{Carlos Eduardo Ferreira Monteiro ${ }^{4}$}

Universidade Federal de Pernambuco, Departamento de Psicologia e Orientação Educacionais do Centro de Educação, Professor Associado III; Docente de Cursos de Licenciatura e do Programa de Pós-Ģraduação em Educação Matemática e Tecnológica (Edumatec)

https://orcid.org/0000-0003-4355-0793

Resumo: 0 artigo discute sobre uma pesquisa desenvolvida em escolas indigenas que teve como objetivo analisar as possibilidades de promoção do Letramento Estatístico no contexto intercultural do povo Xukuru do Ororubá, para fundamentar a ação docente e estimular o conhecimento matemático dos estudantes por meio de práticas reflexivas. Investigou-se se e como os conteúdos de Estatística eram trabalhados por professores dos anos iniciais do povo Xukuru e analisaram-se o planejamento e a realização de atividades em sala de aula envolvendo as etapas do ciclo investigativo no âmbito de um grupo colaborativo. Utilizou-se a observação participante, a entrevista semiestruturada com três professores indígenas, a análise documental em diários de aula de dois professores e a formação de um grupo colaborativo com a participação de 11 docentes dos anos iniciais do Ensino Fundamental.

Pesquisa Financiada pela Coordenação de Aperfeiçoamento de Pessoal de Nivel Superior (CAPES).

2 Doutora em Educação pela Universidade Federal do Ceará; Mestra em Psicologia Cognitiva pela Universidade Federal do Pernambuco.

3 Mestra em Educação Matemática e Tecnológica pela Universidade Federal de Pernambuco; Doutoranda em Educação Matemática e Tecnológica na Universidade Federal de Pernambuco.

4 Doutor em Educação pela University of Warwick; Mestre em Psicologia Cognitiva pela Universidade Federal do Pernambuco. 
Constatou-se que os professores desta etnia, em termos gerais, desenvolvem um trabalho inicial com a Estatística, valorizando as características culturais da comunidade indigena com atividades interdisciplinares de construção de gráficos e tabelas e incluem também a pesquisa estatística por meio de atividades com intervenções nos diferentes espaços das aldeias. As vivências no grupo colaborativo possibilitaram experiências significativas sobre o ciclo investigativo, possibilitando a ampliação de habilidades.

Palavras-chave: Educação estatística. Educação escolar indigena. Educação Matemática Crítica. Formação de professores.

Abstract: The article discusses a study developed in indigenous schools which aimed to analyze the possibilities of promoting the Statistical Literacy in the intercultural context of the Xukuru people of Ororubá, to base the teaching action and to stimulate the mathematical knowledge of the students through reflective practices. We investigate if and how the statistical contents were worked by initial years teachers of Xukuru people and analyze the planning and carrying out of classroom activities involving the stages of the investigative cycle within a collaborative group. The methodological methods involved participant observation and semistructured interviews with three indigenous teachers; documentary analysis in two teachers' class journals and the formation of a collaborative group with the participation of 11 teachers from the initial years of Elementary School. It was found that the teachers of this ethnic group develop an initial work with statistics valuing the cultural characteristics of the indigenous community with interdisciplinary activities of construction of charts and tables, which included the statistical research through activities with interventions in the different spaces of the villages

Keywords: Statistical education. Indigenous school education. Critical Mathematics Education. Teacher education.

Resumen: El artículo discute una investigación desarrollada en escuelas indígenas que tuvo como objetivo analizar las posibilidades de promoción de la lectura estadística en el contexto intercultural del pueblo Xukuru del Ororubá, para fundamentar la acción docente y estimular el conocimiento matemático de los estudiantes por medio de prácticas reflexivas. Se investigó si y cómo los contenidos de estadística eran trabajados por profesores de los años iniciales del pueblo Xukuru y se analizó la planificación y realización de actividades en el aula involucrando las etapas del ciclo de investigación en el marco de un grupo colaborativo. Se utilizó la observación participante, entrevista semiestructurada con tres profesores indígenas, análisis documental en diarios de clase de dos profesores y formación de un grupo colaborativo con la participación de 1 docentes de los años iniciales de la Enseñanza Fundamental. Se constató que los profesores de esta etnia, en términos generales desarrollan un trabajo inicial con la estadística valorizando las características culturales de la comunidad indígena con atividades interdisciplinarios de construcción de gráficos y tablas e incluyen también la investigación estadística por medio de actividades con intervenciones en los diferentes espacios de las aldeas. las 
vivencias en el grupo colaborativo posibilitar experiencias significativas sobre el ciclo de investigación, posibilitando la ampliación de habilidades.

Palabras clave: Educación estadística. Educación escolar indígena. Educación matemática crítica. Formación de professores.

Recebido em 9 de agosto de 2018

Aceito em 17 maio de 2019

Publicado em 05 de julho de 2019

\section{INTRODUÇÃO}

0 interesse pela democratização e acessibilidade dos conhecimentos escolares de Estatística para populações de contextos socioculturais distintos nos incentiva a abordar neste artigo elementos de um estudo que investigou a Educação Estatística e como esse conhecimento transita em espaços interculturais, como o universo das escolas indígenas. Fundamentados nos princípios da Educação Matemática Crítica, buscamos abordar a relevância de fomentar o acesso aos conhecimentos de Estatística para todos os povos indígenas mediante suas especificidades culturais. Esses povos enquanto cidadãos precisam entender criticamente as informações estatísticas para poderem se comunicar com o mundo dentro e fora das aldeias, para que possam realizar pesquisas sobre a comunidade em que vivem e, sobretudo, para que construam conhecimentos baseados em seus diversificados ambientes de vida.

A Educação Estatística tem sido incluída em diversas discussões no Brasil e internacionalmente, associada a sua importância para a cidadania. Os debates se debruçam a respeito do valor e da relevância do conhecimento de os conteúdos de Estatística estarem presentes nos currículos da Educação Básica, para estimular o desenvolvimento de habilidades voltadas à leitura e análise de inúmeros dados reais (CAZORLA; KATAOKA; SILVA, 2010; BATANERO; BURRILL; READING, 2011).

Cazorla e Castro (2008) discutem que a introdução de conteúdos estatísticos se constitui em uma possibilidade de atender a uma demanda social que é o letramento estatístico das pessoas. Essas autoras mencionam a importância de os individuos estarem aptos para tomar decisões conscientes, sem se deixar levar pelas armadilhas impostas nas informações apresentadas frequentemente em gráficos e tabelas veiculadas nas diversas mídias.

Gal (2002, 2019) salienta que nos processos de ensino e aprendizagem de Estatística, é necessário considerar os aspectos relacionados com a aquisição e desenvolvimento de habilidades técnicas, compreensões conceituais e processos subjetivos do sujeito, como 
Liliane Maria Teixeira Lima de Carualho, Sérgia Andréa Pereira de Oliveira, Carlos Eduardo Ferreira Monteiro

atitudes e postura crítica. 0 conjunto desses elementos inter-relacionados compõe o modelo de Gal sobre letramento estatístico.

Skovsmose (2014) desenvolve a abordagem da Educação Matemática Crítica (EMC) e traz uma importante discussão a respeito do papel social da Matemática em favor da democracia, pois compreende o ensino dos conteúdos matemáticos como uma possibilidade de os indivíduos desenvolverem suas capacidades críticas em qualquer contexto. Esse aporte teórico pode articular-se com a perspectiva de letramento estatístico de Gal (2002, 2019). Para esse pesquisador, o conhecimento dos conteúdos matemáticos, impulsionado por uma aprendizagem significativa, é capaz de conceder poder, desenvolver capacidades, propiciar autonomia e estimular os indivíduos a refletir, conhecer e avaliar suas perspectivas ou oportunidades na vida. 0 ensino da Matemática, para esse pesquisador, precisa incluir em sala de aula o debate sobre temas ligados ao poder, pois leva em consideração os aspectos políticos da Educação Matemática praticada.

Como no modelo de Gal (2002, 2019), na perspectiva de Skovsmose (2014) os aspectos subjetivos do indivíduo são considerados importantes para os processos de aprendizagem. Assim, na abordagem da Educação Matemática Crítica, foi incorporada a noção de foreground, a qual se refere às intenções, expectativas e aspirações que os estudantes possuem no âmbito de suas oportunidades sociais, políticas, econômicas e culturais. Nesse sentido, para a EMC o trabalho docente precisa estar vinculado a um redimensionamento das atividades pedagógicas para incluir cenários de investigação associados à realidade dos estudantes.

A abordagem do letramento estatístico que defendemos neste artigo se interliga com uma perspectiva da EMC que se situa para além do ensino de conteúdos e requer um trabalho que se desenvolva em uma perspectiva intercultural colaborando para a emancipação dos sujeitos. No âmbito da educação escolar indígena, a educação estatística pode ser vista em uma perspectiva de promover nos sujeitos uma forma de análise crítica da realidade na qual os sujeitos se inserem.

Bernardi, Caldeira e Duarte (2013) ressaltam a importância da Educação Matemática Crítica para oportunizar a todos os povos a possibilidade de sistematizar o conhecimento com base nas peculiaridades de seu contexto cultural. Acredita-se que o trabalho com a estatística em uma perspectiva crítica assume uma dimensão política e educativa para a construção de uma democracia, pois pode oferecer ferramentas imprescindíveis para que os povos indígenas, possam emitir opinião, interpretar, pesquisar e registrar as informações mediante o ambiente onde estão inseridos e também extrapolar fronteiras.

Neste artigo entende-se que a inclusão da interculturalidade em todas as etapas da educação escolar indígena é uma abordagem democrática das políticas, que, se garantida, poderá contribuir para assegurar os direitos dos povos indígenas, bem como promover o 
respeito às diferentes formas tradicionais de conhecimento e valorizar as singularidades e as pluralidades na educação formal.

\section{LETRAMENTO ESTATÍSTICO ENTRE POUOS CULTURALMENTE DISTINTOS}

0 letramento estatístico é uma demanda social baseada na evidência de que a estatística está presente em diversas situações do cotidiano. Rumsey (2002) exemplifica essa realidade quando afirma que trabalhar com essa temática é educar para a cidadania, pois a aprendizagem de conteúdos estatísticos possui relevância para a vida diária e é tão importante quanto a aprendizagem da leitura e da escrita, em uma alusão à aprendizagem da língua portuguesa. Um exemplo, segundo esse autor, está na quantidade de informações estatísticas que são propagadas pela mídia diariamente, requerendo do cidadão aprendizagens específicas.

Cazorla e Utsumi (2010) caracterizam a Estatística como uma ciência que permeia a vida dos cidadãos e que auxilia outras ciências, na medida em que fornece procedimentos para coletar, analisar e tratar dados. 0 conhecimento dos aspectos que permeiam a Educação Estatística é ferramenta cada vez mais necessária para a convivência diária dos indivíduos de qualquer etnia. Um dos grandes desafios que se apresentam aos educadores é o de refletir a respeito dos processos de ensino e aprendizagem de estatística, tendo em vista subsidiar uma demanda social voltada à formação de cidadãos letrados estatisticamente.

Uma abordagem envolvendo a ideia de letramento estatístico também é oferecida por Gal (2002, 2019). De acordo com esse autor, para uma pessoa ser considerada letrada em Estatística, ela precisa desenvolver aspectos relacionados a conhecimentos específicos do conteúdo, a dimensões cognitivas e à dimensão denominada de disposicional e que diz respeito à postura crítica, crenças e atitudes das pessoas. Outro ponto a considerar são algumas habilidades e competências necessárias para que o sujeito seja de fato letrado estatisticamente, como saber por que os dados são necessários e como os dados podem ser produzidos; familiaridade com termos e ideias básicas relacionados à Estatística e exibições gráficas; compreender as noções básicas de probabilidade e compreender como as conclusões ou inferências estatísticas são alcançadas.

Portanto, ao repensar os processos de ensino e aprendizagem de Estatística em uma proposta intercultural, é necessário ter a atenção de não reduzir a interculturalidade a apenas algumas situações ou atividades pedagógicas pontuais. Por ser uma proposta que perpassa o currículo, pode ser uma possibilidade contra a exclusão social dentro da escola, sendo repensada e realizada no sistema escolar como um todo. 
Visto dessa forma, entende-se como essencial, e que não se pode ignorar, a necessidade da inclusão dos conceitos estatísticos para a formação dos sujeitos que vivem em comunidades indígenas. Bernardi, Caldeira e Duarte (2013) colocam-nos que a escola indígena é um espaço de permanente construção da identidade onde os povos remanescentes podem estabelecer diferentes relações com a sociedade de modo a fortalecer e reafirmar suas especificidades culturais. Greenman e Ramos (2009) consideram que a principal característica da interculturalidade é o diálogo e o tratamento igualitário entre todas as culturas, em que nenhuma possa ser considerada como cultura dominante e/ou subordinada, mas que todas possam ser reconhecidas e, sobretudo, valorizadas. Portanto, diante de pluralidades étnicas e culturais dos indígenas brasileiros, faz-se necessária uma nova postura e pensamento dos professores sobre os processos educacionais, não só relativos aos conteúdos de Estatística, mas sobre o currículo como um todo. Estes precisam ser pensados considerando o respeito e a valorização das diversidades culturais na formação dos sujeitos.

Ao pensar o letramento estatístico para povos remanescentes, como é o caso do povo indígena Xukuru do Ororubá, compreendemos que é crucial o trabalho dessa temática em uma perspectiva intercultural, pois este pode ser um dos caminhos que contribuirão para a valorização do saber e da cultura tradicional de cada povo e, ao mesmo tempo, dar-lhe condições de enfrentar as e participar ativamente das demandas sociais. Candau e Russo (2010) destacam que a interculturalidade na educação deve ser vista como uma prática social de grande importância, por possibilitar que sujeitos que possuem diferentes perspectivas de vida, costumes e/ou culturas se integrem e se valorizem por meio de uma construção coletiva de saberes.

Considerando a importância da atuação docente para o ensino de estatística, o professor necessita estar preparado para engajar os alunos por meio da formulação de problemas que possam ser respondidos via coleta, organização, análise de dados e interpretação dos resultados de acordo com o contexto.

Acredita-se que não incluir um trabalho sistemático com a estatística na formação inicial do professor cria lacunas nos processos de aprendizagem. Se o docente não compreende essa temática em sua formação e não busca esse conhecimento em outras fontes, pressupomos que a prática pedagógica também ficará comprometida, pois dificilmente ele conseguirá envolver os estudantes em uma aprendizagem significativa.

De acordo com Souza (2008), nas escolas do povo Xukuru os docentes procuram alcançar uma aprendizagem significativa, desenvolvendo uma prática pedagógica baseada em um contexto intercultural, com conteúdos curriculares do ensino formal, aliados aos aspectos culturais do povo. Estudos e reflexões a respeito da Educação Estatística como uma prática social em escolas de povos indígenas ainda são escassos, entretanto, identificamos na literatura o estudo de Barbosa e Magina (2014) e o estudo de Mota et al. (2013). 
0 estudo de Barbosa e Magina (2014) resultou da inquietação dessas autoras para compreender qual tratamento deveria ser dado à Matemática em escolas indígenas e de que modo tem sido favorecido o processo de aprendizagem dos alunos. Propuseram, então, em colaboração com os indígenas, a realização de um estudo que objetivou discutir - currículo de Matemática do Programa de Educação de Jovens e Adultos Guarani (EJA Guarani), que estava sendo desenvolvido com a comunidade indígena da aldeia Sapukai, desde o ano de 2012. As autoras perceberam que os estudantes tinham mais facilidade em aprender os conceitos e entender a sua aplicabilidade quando eles eram vinculados com a vida cotidiana da aldeia. Especificamente sobre a Estatística, Barbosa e Magina (2014) discutem que os estudantes, após realizarem uma atividade de interpretação de gráficos, se sentiram mais motivados em buscar informações mais atualizadas sobre o uso da terra indígena para sobrevivência e acerca dos direitos indígenas sobre elas. As autoras concluem enfatizando a importância de valorizar a Matemática como um produto cultural e de proporcionar aos estudantes indígenas processos de aprendizagem nos quais eles utilizem e valorizem a Matemática produzida pela comunidade.

Mota et al. (2013) realizaram um estudo em um curso de Licenciatura em Educação Básica Intercultural buscando oferecer aos estudantes uma oficina de Estatística Aplicada à Escola Indígena. Os autores discutiram com 133 alunos do Curso de Licenciatura o conhecimento sobre a Estatística Básica para que eles pudessem compreender, planejar, executar e interpretar dados estatísticos. Durante uma semana, foi realizada uma oficina no componente curricular Tecnologia da Informação e Comunicação (TIC) focando na construção de gráficos e na contextualização das informações com a realidade das comunidades indígenas por meio do programa Microsoft Excel. Os autores concluíram que, por meio do trabalho com a Educação Estatística aliado com o uso do recurso da tecnologia, os licenciandos realizaram atividades de interpretação e construção de gráficos percebendo os limites e as possibilidades da inclusão de conteúdos estatísticos na escola indígena. Assim, puderam ampliar a compreensão sobre a realidade das aldeias indígenas e, ainda, perceber a Estatística como um tipo de linguagem que possibilita uma análise ampla do mundo, em um constante diálogo intercultural com as demais áreas do conhecimento escolar.

Essas duas pesquisas mencionadas contribuem para uma ampliação da discussão sobre a importância do ensino de Estatística na educação escolar indígena. Em particular, revelam a importância da Estatística como uma ferramenta que proporciona às comunidades indígenas ações como coleta e organização de informações relevantes para o meio em que vivem. Além disso, possuem relevância, na medida em que apontam que aspectos socioculturais podem ser utilizados na Educação Estatística de diferentes povos indígenas. 


\section{EDUCAÇÃO MATEMÁTICA CRÍTICA E EDUCAÇÃO INDÍGENA}

A Educação Matemática Crítica (EMC), de acordo com Skovsmose (2014), preocupase com aspectos funcionais da Matemática para que os sujeitos adquiram e/ou aprimorem as habilidades necessárias para entender, produzir e aplicar os conceitos teóricos em qualquer situação na vida. Nesse sentido, a EMC pode ser entendida por uma variedade de reflexões sobre as competências que envolvem o ensino e a aprendizagem da matemática e suas implicações no cotidiano, como seu impacto social, político e cultural. Considerando as demandas sociais no sistema escolar, Skovsmose (2014) oferece-nos uma perspectiva importante do papel da Matemática, pois nos ajuda a refletir com ideias de cunho metodológico e filosófico sobre a tarefa de educar para a cidadania.

Quatro pontos principais da Educação Matemática Crítica são destacados por Skovsmose (2014). 0 primeiro refere-se à importância da relação professor-aluno; o segundo ponto diz respeito à importância de um currículo crítico; o terceiro relaciona-se com a questão do direcionamento dos processos de ensino-aprendizagem a problemas; e o quarto ponto elenca os cenários para investigação.

No que concerne à importância da relação professor-aluno, o autor afirma que, em uma educação crítica e democrática, é necessário existirem igualdades entre os dois agentes principais da aprendizagem, o professor e o aluno. A comunicação por meio do diálogo se configura como um dos agentes principais no processo de ensino e de aprendizagem, conforme já mencionamos, pois é por meio do diálogo que o professor pode inibir ou estimular o estudante, uma vez que a comunicação é carregada de sentidos, de valores e tem a capacidade de produzir e mudar ações.

0 segundo ponto destacado por Skovsmose (2014), currículo crítico, envolve uma discussão sobre o fato de o currículo carregar objetivos e não ser neutro. Trazendo essa discussão especificamente para a sala de aula, é essencial que os docentes, ao trabalhar com um conteúdo matemático, previamente reflitam a respeito da aplicabilidade do assunto, dos interesses envolvidos e da relevância que esse conteúdo tem para a vida dos estudantes.

No tocante ao direcionamento do processo de ensino e aprendizagem por meio de cenários de investigação, aquele pesquisador remete a discussão para a inclusão, nos planejamentos de aula, de situações que gerem reflexões sobre a utilização da matemática em acontecimentos do cotidiano. Nesse cenário, o aluno se torna investigador do processo de ensino e aprendizagem e o professor atua incentivando a reflexão e a curiosidade dos alunos. Assim, promove-se o engajamento voluntário dos estudantes para trabalhar com assuntos de seus interesses por meio de investigação. 
Skovsmose (2014) sugere um redimensionamento das atividades didáticopedagógicas, visando contemplar os anseios de professores e estudantes por meio de cenários de investigação que favorecem práticas de sala de aula que contrastam com práticas baseadas em listas de exercícios. Pensa-se na elaboração de um ambiente de aprendizagem no qual os estudantes estejam interessados em participar, colaborativamente com o educador, com base em atividades de investigação sobre temas de interesse do grupo.

Um dos aspectos fundamentais para incentivar uma aprendizagem significativa capaz de empoderar os sujeitos sobre suas oportunidades na vida e de fazê-los conhecer e avaliar suas perspectivas encontra-se relacionado a mudanças metodológicas que contribuam para tornar alunos e professores protagonistas na ação educativa. Um caminho para alcançar uma aprendizagem significativa, segundo Skovsmose (2014, p. 45), é a ideia de cenários de investigação. Um cenário seria "um terreno sobre o qual as atividades de ensino e de aprendizagem acontecem." A apresentação desse terreno para os alunos pode vir a se configurar em "momentos de abertura de possibilidades de sentido." (SKOVSMOSE, 2014, p. 46). Um importante aspecto para se alcançar essa aprendizagem é desenvolver em sala de aula um ensino com base no processo de diálogo propiciado pelas interações aluno-aluno e aluno-professor. A realização de atividades de pesquisa, segundo esse pesquisador, seria uma oportunidade para criar cenários para investigação, pois a pesquisa se encontra fortemente vinculada a aspectos da intencionalidade e requer o envolvimento de professores e alunos.

De acordo com Skovsmose (2014), um dos grandes desafios na Educação Matemática é romper com os processos sociais excludentes implícitos ou explícitos na escola e assegurar a todos os estudantes um papel de protagonistas nos processos de ensino e de aprendizagem. Skovsmose (2008, p. 160) considera que a importância dada ao background dos sujeitos pode fomentar processos formativos significativos e destaca que é preciso ir além e oportunizar a investigação e o desenvolvimento do foreground, que consiste na forma como as pessoas "interpretam suas possibilidades, tomando como referência seu contexto político, cultural, econômico e sua própria posição social."

0 ensino de conteúdos de Estatística visto dessa maneira pode ter um papel emancipatório para as comunidades indígenas, na medida em que favorece a valorização do background dos sujeitos e considera as dimensões sociais, cultural, política e econômica em que uma pessoa se insere, bem como suas expectativas futuras, ou os seus foregrounds. Assim, oferece condições para que eles possam adquirir o conhecimento matemático tradicional de seu povo, juntamente com a matemática institucionalizada, considerando as relações de poder envolvidas (BERNARDi; CALDEIRA; DUARTE, 2013).

A emancipação dos sujeitos é, para Skovsmose (2014), uma tarefa da educação matemática crítica e se compõe como resultado de uma prática educativa crítica, que procura responder a demandas críticas da sociedade, as chamadas crises sociais. Dessa maneira, 
as práticas de ensino envolvendo o conhecimento de estatística precisam ser focadas na mudança social e na valorização dos sujeitos.

\section{O POUO XUKURU DE ORORUBÁ}

Pioneiros no Estado de Pernambuco nas lutas em prol da garantia dos direitos dos povos indígenas, o povo Xukuru do Ororubá se localiza no Agreste pernambucano, especificamente na Serra do Ororubá, no Município de Poção e também em alguns bairros da Cidade de Pesqueira, a aproximadamente $215 \mathrm{Km}$ de Recife. De acordo com Silva (2008), o povo Xukuru possui uma população com mais de 10 mil índios distribuídos em 32 aldeias. Em razão da localização geográfica das aldeias, estas são chamadas de regiões Agreste, Serra e das Águas. De acordo com Almeida (2001, p. 6), o nome do povo Xukuru do Ororubá significa respeito do índio com a natureza, conforme o extrato de fala do cacique Xikão aponta: "o nome da nossa tribo é Xukuru do Ororubá, significa o respeito do índio com a natureza. Ubá é um pau, Uru é pássaro que tem na mata, aí faz a junção, e fica: Xukuru do Ororubá, o respeito do índio com a natureza."

Com o reconhecimento de que se constituem em povo de uma identidade étnica específica e diferenciada, o povo Xukuru do Ororubá tem desenvolvido, por meio de diversas representações, culturais, religiosas e sociais, mecanismos políticos e coletivos que buscam garantir a manutenção e o fortalecimento de sua própria cultura. Conscientes de seu papel na sociedade, os Xukuru entendem que a educação escolar é um mecanismo de confronto para as contradições da sociedade e a consideram como uma ferramenta de fortalecimento para sua identidade étnica.

Esse povo, ao longo de sua história de resistência e luta, buscou a preservação e a valorização da sua identidade étnica, por meio de uma organização sociopolítica baseada em conselhos internos como é o caso do Conselho de Educação e do Conselho de professores indígenas Xukuru do Ororubá (Copixo). Assim, coletivamente o povo Xukuru do Ororubá discute e decide sobre todas as ações pretendidas para a comunidade. No Copixo são definidos os planos de aula e as ações educacionais que serão realizadas nas escolas do povo Xukuru. A pesquisa discutida neste artigo precisou ser apresentada ao Conselho para que fosse dado o consentimento.

Em se tratando especificamente dos conteúdos curriculares de Matemática, Arcanjo (2006) destaca que o povo Xukuru de Ororubá entende que esses conhecimentos se fazem necessários para a sobrevivência de seu povo, pois a Matemática está presente em todo o cotidiano de suas aldeias. Nesse sentido, esse componente curricular apresenta grande importância no Projeto Político-Pedagógico das escolas dessa comunidade. 
Esse povo vem buscando transcender as exclusões sociais que, por vezes, colocam não só a cultura, mas também a sua existência em risco, pela busca de autonomia e fortalecimento de suas especificidades dentro da escola. É utilizando a função social da escola que o povo Xukuru procura construir mudanças por meio do conhecimento e da conscientização dos sujeitos.

\section{MÉTODO}

Para adentrar no universo dos sujeitos pesquisados e entender as informações a partir da realidade sociocultural do povo Xukuru do Ororubá, utilizamos a observação participante, entrevistas e análise documental. Para além desses instrumentos de pesquisa mencionados, também focamos na formação de um grupo colaborativo para discussão, desenvolvimento e análise de conteúdos de Estatística, sendo essa abordagem um dos aspectos mais significativos em nosso trabalho.

A opção por essa abordagem metodológica se deu por entendermos que práticas colaborativas na formação do professor podem contribuir para o protagonismo dos docentes, pois eles passam a desenvolver um papel ativo na produção dos dados. Paralelamente, observamos ser essa a prática já realizada pelos professores Xukuru do Ororubá em suas assembleias, como o Conselho de professores indígenas Xukuru do Ororubá (Copixo). Autores como Fiorentini (2004) discutem a importância do trabalho colaborativo nas atividades docentes, por reconhecerem o seu potencial na promoção de processos de ensino e de aprendizagem com mais significado. Uma das ideias fundamentais da Abordagem Colaborativa é de que o conhecimento é construído socialmente na interação entre os indivíduos. Assim, considera-se que um dos principais objetivos do trabalho colaborativo é a co-construção do conhecimento sem que haja a supremacia do conhecimento do pesquisador sobre o conhecimento e a cultura dos pesquisados.

Especificamente na formação continuada do professor indígena, Bernardi (2011) discute que o trabalho colaborativo possibilita aos docentes uma constante reflexão sobre sua prática pedagógica, que se reflete em um desenvolvimento mais significativo dos processos de ensino e aprendizagem de Matemática. Portanto, o trabalho colaborativo se apresenta como uma possibilidade para o professor indígena se tornar o principal protagonista de seu desenvolvimento profissional e de transmitir esse conhecimento para sua comunidade.

A formação do grupo colaborativo visou, sobretudo, possibilitar o protagonismo dos docentes por meio da discussão, desenvolvimento a análise de atividades pedagógicas relacionadas à Educação Estatística. Com a finalidade de coletar os dados para posterior 
análise, foi utilizada uma câmera de vídeo para gravar integralmente todos os encontros com - grupo colaborativo. A observação participante e a entrevista semiestruturada foram os instrumentos de pesquisa em que nos apoiamos para conhecer a realidade dos sujeitos e embasar a formação do grupo colaborativo.

A entrevista semiestruturada foi realizada seguindo-se um roteiro prévio, constituído por questões vinculadas ao perfil dos entrevistados (formação inicial e continuada), conhecimentos prévios sobre Estatística (o significado da Estatística), planejamento de aula para os conteúdos de Estatística, desenvolvimento de atividades de Estatística (livros didáticos, conteúdos de Estatística) e construção e interpretação de gráficos. As entrevistas foram realizadas com três docentes indígenas dos anos iniciais do Ensino Fundamental e aconteceram em momentos e em locais diferentes mediante a disponibilidade de cada uma delas. Para preservar a identidade das entrevistadas utilizamos os nomes fictícios Toipa (mãe), Jetuin (menina) e Sacarema (mulher). Esses nomes são parte do vocabulário do povo Xukuru encontrado no livro Xukuru Filhos da Mãe Natureza (ALMEIDA, 1997). Todas as interlocuções foram gravadas e os dados transcritos e organizados para posterior análise. É importante destacar que a participação dos docentes neste estudo ocorreu à medida que foram se desenvolvendo as primeiras negociações para a entrada nos espaços do povo Xukuru do Ororubá.

Para ampliar as informações obtidas com as entrevistas, também investigamos os diários de aulas de duas docentes que tiveram interesse em conceder o material: Jetuim e Toipa. 0 objetivo desse procedimento metodológico foi identificar como o conteúdo de Estatística se apresentava nos planejamentos pedagógicos e na prática docente. Para tanto, utilizamos uma câmera fotográfica e uma câmera filmadora para registrar cada página dos diários para posterior análise.

Além dos procedimentos mencionados, na trajetória da pesquisa também foi utilizada a observação participante no âmbito de todas as ações e no desenvolvimento das interações com os sujeitos. Portanto, foi possível compreender a realidade observada durante as visitas às aldeias indígenas, nas interações com professores e lideranças, na participação em reuniões e no convívio com o grupo colaborativo.

Por meio dos instrumentos de pesquisa supracitados, analisamos os dados obtidos na pesquisa elencando categorizações que nos permitiram desenvolver um trabalho sistemático em conformidade com os objetivos do estudo. A seguir, apresentamos uma discussão a respeito da análise dos resultados mediante nosso percurso metodológico. Discutimos na seção seguinte alguns resultados obtidos por meio dos instrumentos de pesquisa. 


\section{RESULTADOS}

Inicialmente apresentamos uma discussão dos dados da entrevista semiestruturada; em seguida, discutimos aspectos dos dados dos diários de aula das participantes e os dados produzidos no grupo colaborativo; por fim, apresentamos e discutimos as atividades dos estudantes anexadas ao relatório entregue pelos professores participantes ao final dos trabalhos no grupo colaborativo.

\subsection{ENTREUISTA SEMIESTRUTURADA}

As três docentes que foram entrevistadas, Toipa, Jetuin e Sacarema, são pedagogas e duas delas afirmaram nunca ter estudado ou recebido orientações para $\circ$ trabalho com a Estatística, tanto na formação inicial quanto na formação continuada. Apenas a professora Jetuin referiu ter recebido orientações durante sua graduação no componente curricular Didática.

Com relação ao trabalho pedagógico, todas as professoras mencionaram que costumam relacionar os conteúdos do ensino regular com conteúdos específicos do povo Xukuru e que essa forma de abordagem é parte de uma tradição no contexto das aldeias, onde, geralmente, desenvolvem-se práticas interculturais. Todas as entrevistadas também informaram que já trabalharam com a Estatística, seja com pesquisa ou com a construção e interpretação de gráficos em sala de aula. Segundo as participantes, o gráfico de barras é a representação estatística que elas mais utilizam em atividades de sala de aula, pois possuem maior familiaridade, conforme extrato de fala:

\footnotetext{
Eu trabalho de forma diferenciada, eu não vou está colocando isso aqui é estatística, mas eu levo a prática. Aulas de campo, de comparativos, de quantidades e as trilhas agora que a gente faz, que é um projeto didático que se chama Xikão Xukuru guerreiro da paz. Nós usamos a trilha como uma estratégia, para ver a comunidade, questões de água, questões de terra, de plantação. Então, quando nos voltamos para a escola, tudo que foi visto é relatado em gráficos, por exemplo, a plantação de fulano tem tal coisa, mas a da gente não tem. Então, por que não tem? Então, a gente relata isso em gráficos de pizza e gráfico de barras, por que é início então eu trabalho a construção e interpretação junto com eles. (Jetuin) (informação verbal).
}

Com base nesse relato, observa-se uma preocupação da professora com a elaboração de metodologias para o ensino de estatística que coloca o aluno como protagonista da aprendizagem, por meio de um trabalho contextualizado com base no cotidiano dos 
estudantes na comunidade. 0 processo formativo dos estudantes Xukuru, ao que parece, perpassa o ambiente escolar e percorre a vida das aldeias, se inter-relacionando com as atividades socioculturais desse povo.

\subsection{DIÁRIOS DE AULA DE JETUIM E TOIPA}

0 diário de Jetuim consistia em um material enviado pela Secretaria de Educação de Pernambuco para descrever seu planejamento ao longo do ano letivo. Nele estavam registradas 139 aulas, entre os períodos de fevereiro a outubro de 2014 direcionadas para uma turma do $5^{\circ}$ ano. No entanto não foi possível encontrar nenhuma descrição de atividades que envolvessem o trabalho com os conteúdos estatísticos. Além de uma caracterização das aulas, pudemos encontrar no diário um modelo de organização que inclui três itens chamados de Terra, Identidade e Interculturalidade, no qual a docente deve descrever os exos temáticos, os conteúdos, os temas e os objetivos a serem construídos pelos estudantes.

Segundo Ramos (2009), a noção de interculturalidade implica relação, diálogo e comunicação dos indivíduos entre as distintas culturas. Na educação, as relações interculturais exigem do professor uma postura baseada no reconhecimento das diferenças culturais e ideológicas, de modo a contribuir para a formação dos estudantes nos diferentes contextos de aprendizagem.

Já o diário de Toipa consistia em um caderno pessoal reservado para esse fim, no qual ela identificava sua turma descrevendo nome, sexo, idade e série dos seus alunos e os registros relativos ao componente curricular, como: conteúdos, objetivos da aula, metodologias, recursos didáticos e os critérios de avaliação.

As duas docentes apresentaram planejamentos com atividades que contemplavam aspectos específicos da cultura do povo Xukuru. Os diários analisados continham aulas que englobavam com mais frequência os componentes curriculares de Português, em seguida, Matemática, Ciências, História, aulas interdisciplinares, Geografia e Artes. Especificamente no planejamento do componente curricular Matemática, os conteúdos de Estatística são contemplados minimamente, em detrimento do bloco de conteúdos de Números e Operações.

Sendo a escola um espaço que favorece a formação da cidadania, é possível perceber que ocorre uma redução dos conteúdos matemáticos em relação aos componentes do currículo. Conjecturamos que os estudantes, em certa medida, estão sendo excluídos socialmente uma vez que o ambiente escolar não favorece a aprendizagem de conteúdos que são imprescindiveis para estimular e desenvolver uma postura crítica diante da sociedade. Assim, corroboramos com as discussões de Skovsmose (2008), ao enfatizar a importância 
de situações de ensino da Matemática interligadas a processos sociopolíticos em que o conhecimento seja capaz de favorecer o protagonismo dos sujeitos. Portanto, pode não ser suficiente a escola trabalhar com os estudantes apenas com os números e operações, pois é necessário aliar o conhecimento matemático a outros conhecimentos para permitir uma postura reflexiva.

\subsection{GRUPO COLABORATIUO}

Com relação à formação do grupo colaborativo, foi decidido anteriormente em negociações com as coordenadoras dos professores das escolas do povo Xukuru do Ororubá que durante o primeiro encontro com as participantes seriam estabelecidos colaborativamente os objetivos do grupo e a prática metodológica a ser desenvolvida. Foram realizados quatros encontros presenciais, sendo fixadas quatro horas sem intervalo para almoço, totalizando 20 horas de carga horária durante os meses de junho a agosto de 2015.

0 grupo colaborativo teve a adesão voluntária de noves professores dos anos iniciais do Ensino Fundamental e de dois coordenadores do mesmo nível de ensino das escolas indígenas do povo Xukuru do Ororubá. A cada encontro o grupo discutia e decidia sobre o conteúdo a ser trabalhado no encontro posterior, tendo como meta a discussão conceitual e a elaboração e a realização individual de um plano de aula direcionado para o trabalho com conteúdos de Estatística. Além disso, buscou-se potencializar uma formação crítica nos estudantes por meio de práticas pedagógicas que repercutissem as especificidades culturais do povo Xukuru.

Com o propósito de sistematizar e socializar o trabalho realizado por cada docente, - grupo decidiu que seria necessário que os professores, após realizarem seu planejamento de aula com os conteúdos de Estatística, elaborassem um relatório para descrever como as ações foram desenvolvidas no trabalho com os alunos. No primeiro encontro discutiu-se sobre Estatística e Letramento estatístico, utilizando-se análise coletiva e discussão de dados reais apresentados em gráficos e tabelas. 0 segundo encontro focou em discussões sobre leitura crítica e sobre as expectativas de aprendizagem em Estatística a partir de orientações curriculares nacionais. No terceiro encontro o foco foi o tratamento da informação, em particular dos aspectos conceituais da construção e interpretação de gráficos e tabelas e elaboração do planejamento de aula. Após esse encontro os professores realizaram os seus planejamentos nas escolas e socializaram os resultados no último encontro do grupo colaborativo. Este ficou destinado à socialização dos resultados com todos os participantes e também a uma avaliação individual sobre o desenvolvimento das atividades do grupo. 
Na elaboração do plano de aula os docentes propuseram um trabalho de investigação sobre os recursos hídricos existentes nas aldeias e elencaram a pesquisa como eixo estruturador para o desenvolvimento dos planejamentos. Além disso, apresentaram uma proposta de atividades contextualizadas para a realidade das aldeias, abordando elementos específicos da cultura Xukuru por meio de debates, pesquisas e envolvendo um trabalho interdisciplinar dos conteúdos de Estatística aliados a outros componentes curriculares, como Ciências.

Quanto às análises das atividades realizadas pelos estudantes anexadas aos planejamentos dos docentes, consideramos que estes puderam vivenciar uma aprendizagem significativa e crítica. Experimentaram a oportunidade de realizar as etapas do ciclo investigativo por meio do trabalho em grupo e de pesquisa de campo, discutindo a temática a partir do enfoque de suas aldeias e realizando a coleta de dados por meio de entrevistas com a comunidade. Além disso, demonstraram possuir um senso numérico razoável para exprimir os resultados de pesquisa, pois estimaram quantidades e as representaram graficamente por meio de setores e de barras.

Contudo, aspectos conceituais específicos na construção de gráficos ainda são necessários para aprimorar o letramento estatístico dos estudantes, em particular aqueles relacionados com a organização e a sistematização das informações estatísticas e o uso da escala no gráfico de barras.

Consideramos que os participantes do grupo colaborativo, ao realizarem os planejamentos de aula, propiciaram situações que contribuíram para o fortalecimento da identidade indígena dos estudantes, oportunizando a ampliação do conhecimento estatístico a partir da vivência das etapas da pesquisa estatística como a identificação do problema, coleta e tratamento dos dados.

Portanto, de um modo geral, os docentes das escolas do povo Xukuru buscaram desenvolver um trabalho inicial com a Estatística valorizando as características culturais da comunidade. Apesar de os estudantes realizarem a sistematização dos dados da pesquisa com algumas dificuldades, foi possivel perceber que eles desenvolveram as atividades de forma dialogada professor-aluno, aluno-aluno e ampliaram essa perspectiva por incluir interações com pessoas da comunidade. Além disso, foi visível o esforço para sistematizar conhecimentos sobre conceitos, métodos e procedimentos que envolvem a pesquisa estatística.

Tendo em vista os aspectos observados, nos chamou a atenção o possivel impacto que os trabalhos desenvolvidos nos encontros com esse pequeno grupo pode ter gerado nas escolas, pois os participantes costumavam repassar para os demais colegas os conhecimentos adquiridos durante o processo do grupo, conforme relato de alguns. Esse 
ponto levantado coloca em evidência o fator multiplicador dos trabalhos desenvolvidos no grupo que, a despeito de não ter sido previsto nos objetivos da pesquisa, emergiu como algo relevante e que pode ser explicado em razão, talvez, das práticas de discussão e participação já desenvolvidas na comunidade indígena, colocando em evidência aspectos da cultura desse povo.

\section{CONSIDERAÇÕES FINAIS}

Este trabalho buscou refletir sobre as possibilidades para a promoção do Letramento Estatístico no contexto intercultural do povo Xukuru do Ororubá, de maneira colaborativa com os professores participantes para fundamentar a ação docente e estimular o conhecimento matemático e estatístico dos estudantes por meio de práticas reflexivas.

Conforme as análises dos dados obtidos na pesquisa apontam, as vivências com as discussões conceituais e a prática colaborativa contribuíram para que tanto os docentes quanto os estudantes participantes vivenciassem experiências de aprendizagem de Estatística que lhes possibilitassem ampliar habilidades para compreender, relacionar e refletir criticamente as informações estatísticas.

Acreditamos que este estudo contribuiu para a compreensão e a reflexão de que a Educação Estatística tem uma função social. A partir de um olhar crítico sobre a perspectiva intercultural inserida no ensino de Matemática, mais especificamente sobre os conteúdos estatísticos, buscou-se defender a relevância de elencar as especificidades culturais das comunidades indígenas no trabalho escolar. Colocou-se em evidência que, independentemente do nível de ensino, versa a importância de viabilizar um trabalho pedagógico com a Estatística por meio de temas que interessem e façam parte do cotidiano dos estudantes tendo em vista o desenvolvimento de competências críticas dos sujeitos.

Assim, concluímos reafirmando a importância de contribuir para o desenvolvimento do pensamento e do letramento estatístico para os povos indígenas, no sentido de oferecer a oportunidade a cada sujeito de compreender e avaliar as informações presentes nos diversos contextos e de contribuir para promover a igualdade social.

\section{REFERÊNCIAS}

ALMEIDA, E. A. A Política de Educação Escolar Indígena: Limites e Possibilidades. 2001. 195 f. Dissertação (Mestrado em Educação) - Universidade Federal de Pernambuco, Recife, 2001. 
Liliane Maria Teixeira Lima de Carualho, Sérgia Andréa Pereira de Oliveira, Carlos Eduardo Ferreira Monteiro

ALMEIDA, E. A. (org.). Xucuru filhos da mãe natureza. Olinda: Centro de Cultura Luiz Freire, 1997. 75 p.

ARCANJO, J. A. Construindo políticas e matematizando processos: Etnomatemática e escola Xukuru. 2006. 135 f. Dissertação (Mestrado Profissional em Gestão de Políticas Públicas) - Fundação Joaquim Nabuco, Recife, 2006.

BARBOSA, G. S.; MAGINA, S. M. P. 0 Currículo de Matemática na Educação de jovens e adultos Guarani. Revista em Educação Matemática e Tecnológica lberoamericana, Recife, v. 5, n. 1, p. 1-23, jun. 2014.

BATANERO, C.; BURRILL, G.; READING, C. Teaching Statistics in School Mathematics. Challenges for Teaching and Teacher Education: A Joint ICMI/IASE Study. London: Springer, 2011.

BERNARDI, L. T. M. S.; CALDEIRA, A. D.; DUARTE, C. G. Posição de fronteira e produção de significados na educação matemática indígena. Revista Reflexão e Ação, v. 21, p. 172-190, 2013. Edição especial.

BERNARDI, L. T. M. S. Formação Continuada em Matemática do Professor Indígena Kaingang: enfrentamentos na busca de um projeto educativo. 2011. 266 f. Tese (Doutorado em Educação Científica e Tecnológica) - Universidade Federal de Santa Catarina, Florianópolis, 2011.

CANDAU, V. M. F.; RUSSO, K. Interculturalidade e Educação na América Latina: uma construção plural, original e complexa. Diálogo Educacional, v. 10, n. 29, p. 151-169, 2010.

CAZORLA, I. M.; KATAOKA, V. Y.; SILVA, C. B. Trajetória e Perspectivas da Educação Estatística no Brasil: um olhar a partir do GT 12. In: LOPES, C. E.; COUTINHO, C. Q. S.; ALMOULOUD, S. A. (org.). Estudos e Reflexões em Educação Estatística. Campinas: Mercado de Letras, 2010.

CAZORLA, I. M.; UTSUMI, M. C. Reflexões sobre o Ensino de Estatística na Educação Básica. In: CAZORLA, l.; SANTANA, E. Do tratamento da informação ao letramento estatístico. Itabuna: Litterarum, 2010. cap. 1, p. 9153.

CAZORLA, I.; CASTRO, F. O Papel da Estatística na Leitura de Mundo: o Letramento Estatístico. Publicatio UEPG: Ciências Humanas, Ciências Sociais Aplicadas, Linguística, Letras e Artes, v. 16, p. 45-53, 2008.

FIORENTINI, D. Pesquisar práticas colaborativas ou pesquisar colaborativamente? In: BORBA, M. C.; ARAÚJO, J. L. (org.). Pesquisa qualitativa em Educação Matemática. Belo Horizonte: Autêntica, 2004.

GAL, I. Adult's statistical literacy: meanings, components, responsibilities. International Statiscal Review, v. 70, n. 1, p. 1-25, 2002.

GAL, I. Understanding statistical literacy: About knowledge of contexts and models. In: CONTRERAS, M. M.; LOPEZ-MARTIN, M. M.; MOLINA-PORTLLLO, E. (ed.). Terceiro Congresso Internacional Virtual de Educação Estatística. 2019. Disponível em: www.ugr.es/local/fam126/civest.html. Acesso em: 26 abr. 2019. 
MOTA, V. C. et al. Ensinando gráficos na escola indígena: uma possibilidade de diálogos interculturais. In: CONGRESSO IBEROAMERICANO DE EDUCACIÓN MATEMÁTICA, 7., 2013, Montevidéu. Anais [...]. Montevidéu, 2013. p. 7873-7880.

RAMOS, N. Diversidade cultural, educação e comunicação intercultural: políticas e estratégias de promoção do diálogo intercultural. Educação em Questão, v. 34, n. 20, p. 9-32, 2009.

RUMSEY, D. J. Statistical literacy as a goal for introductory statistics courses. Journal of Statistics Education, v. 10, n. 3, 2002.

SILVA, E. H. Xukuru: Memórias e história dos índios da serra do Ororubá (Pesqueira/PE) 1950-1988. 1. 300 f. Tese (Doutorado em História) - Universidade Estadual de Campinas, Campinas, 2008.

SKOVSMOSE, 0. Desafios e reflexão em educação matemática crítica. Campinas: Papirus, 2008.

SKOVSMOSE, 0. Um Convite à educação Matemática Crítica. Campinas: Papirus, 2014.

SOUZA, S. M. F. de. Saberes docentes, saberes indígenas: um estudo de caso sobre o ensino de ciências entre o povo Xukuru do Ororubá. 2008. १२2 f. Dissertação (Mestrado em Ensino de Ciências) - Universidade Federal Rural de Pernambuco, Recife, 2008.

Endereços para correspondência: Avenida da Arquitetura, s/n, Cidade Universitária, 50740-550, Recife, Pernambuco, Brasil; sergia.andrea@gmail.com 
